\title{
L'écho d'un événement international : les thématiques des textes qui circulent au moment du second siège de Vienne (1683)
}

\section{Cécile D'Albis}

\section{OpenEdition}

\section{Journals}

Édition électronique

URL : http://journals.openedition.org/ifha/7422

DOI : $10.4000 /$ ifha.7422

ISSN : 2198-8943

\section{Éditeur}

IFRA - Institut franco-allemand (sciences historiques et sociales)

\section{Édition imprimée}

Date de publication : 1 décembre 2013

ISSN : 2190-0078

Référence électronique

Cécile D'Albis, « L'écho d'un événement international : les thématiques des textes qui circulent au moment du second siège de Vienne (1683)», Revue de l'IFHA [En ligne], 5 | 2013, mis en ligne le 17 février 2014, consulté le 19 avril 2019. URL : http://journals.openedition.org/ifha/7422 ; DOI : 10.4000/ ifha.7422

Ce document a été généré automatiquement le 19 avril 2019

(CIFHA 


\title{
L'écho d'un événement international: les thématiques des textes qui circulent au moment du second siège de Vienne (1683)
}

\author{
Cécile D'Albis
}

\section{NOTE DE L'ÉDITEUR}

Ce projet a été rendu possible par la bourse post-doctorale Gabriel Monod accordée par l'Institut d'histoire en Allemagne (IFHA Francfort sur le Main) durant l'été 2012.

\section{Introduction}

1 À l'époque moderne, les événements internationaux prennent une place de plus en plus importante dans les processus de communication du pouvoir comme dans les préoccupations des populations. Dans un continent en guerre, où s'entrecroisent les relations culturelles et d'intérêts, où les princes doivent justifier de conflits coûteux et souvent idéologiquement peu justifiables, intérêts partisans, commerciaux et curiosités se rejoignent. Au XVII ${ }^{e}$ siècle, la guerre de Trente Ans, dans laquelle sont impliqués la plupart des pays occidentaux, achève d'assurer l'essor des relations factuelles et des gazettes. La diffusion croissante des récits de sièges, d'événements politiques ou extraordinaires crée des espaces scéniques publics où se transmettent les discours du pouvoir, les valeurs communes, puis de plus en plus aussi rumeurs internationales et opinions divergentes ${ }^{1}$.

2 Prendre compte du récit, de l'épaisseur et de l'ampleur discursive des événements a permis de reprendre leur analyse depuis une vingtaine d'années en envisageant leur 
perception, leur durée et leurs implications ${ }^{2}$. Certains événements ont un relief singulier, dépassent les frontières des États et donnent lieu à un flot de réactions médiatiques remarquable. C'est tout particulièrement le cas du second siège de Vienne par les armées ottomanes en 1683, qui passionne les Européens bien au-delà de la zone concernée directement par la guerre. Les événements eurent une répercussion immédiate extraordinaire, qui dépassait de très loin celle de tout autre événement précédent. Les nouvelles et les rumeurs circulent, les témoignages, les descriptions jour par jour, heure par heure, les textes de louange, sensationnalistes, les poèmes inondent le marché pendant des mois, à partir d'un pic en 1683, c'est-à-dire à chaud, pendant et immédiatement après l'événement. Idéologie et intérêts locaux rejoignent l'expression d'une frénésie "croisée", performative et instrumentale, qui disparaît pourtant rapidement par la suite et se dissout dans une intense mythographie qui n'a jamais cessé de s'alimenter et de fonctionner jusqu'à nos jours.

Bien qu'il s'agisse d'un événement médiatique sans précédent ${ }^{3}$, le second siège de Vienne en lui-même n'a pourtant pas encore bénéficié d'une attention spécifique en ce qui concerne non seulement les textes et leur circulation dans le cadre d'un développement nouveau et transitionnel de la presse au sens large du terme en Europe, mais aussi les thématiques développées dans ces textes, leur soubassement idéologique et culturel et les raisons de leur fabuleux succès.

4 Je voudrais me focaliser ici sur les thèmes qui concentrent l'attention des textes diffusés et sur leur succès idéologique et commercial, en essayant de comprendre leurs motivations et d'analyser leurs variations dans les différents contextes géopolitiques dans lesquels ils sont diffusés, au moment même de l'événement et peu après.

5 Il semble presque impossible de recenser l'ensemble des textes manuscrits et imprimés qui ont circulé immédiatement au moment des événements (entre 1683 et 1685-1686 environ) : certainement plus de $400^{4}$. Un travail considérable serait en outre nécessaire pour retrouver précisément l'origine de ces écrits, les remplois et les copies, les circuits des traductions, ou même leurs auteurs. On commence tout juste aujourd'hui à démêler cet extraordinaire écheveau. J'ai choisi d'entreprendre ce sujet pour une période courte, qui concerne le moment du siège lui-même (juillet-septembre 1683) et la période immédiatement postérieure (jusqu'en 1685), dans une vaste zone méditerranéenne, où les réactions furent particulièrement importantes. Il s'agit de saisir la différence de la portée de l'événement et de sa transmission mais aussi les phénomènes de transfert et de diffusion, et leurs ressemblances. Je me focalise essentiellement ici sur les textes italiens et espagnols qui, de Vienne à Rome et Madrid en passant par les petits États italiens, reprennent les grandes thématiques dont nous allons parler. Entre distance et proximité, participation et indifférence, les textes du second siège de Vienne nous permettent de dessiner un contexte à la fois global et localisé, fondé sur des intérêts et des scènes publiques profondément divergents, mais étroitement connectés.

Mais d'abord, que s'est-il passé à Vienne en 1683 ?

\section{Le second siège de Vienne}

6 La teneur des premiers récits du siège explique la portée ultérieure de l'événement et la manière dont il a été rapporté jusqu'à nos jours : à la fois capital et absent en Europe centrale (en tant qu'événement initial des guerres austro-turques), puisqu'il s'agit avant tout de la défense de Vienne contre une menace issue de la faiblesse et de la division du 
pays. Qualifié de "lieu de mémoire européen" par un ouvrage récent, Europäische Erinnerungsorte ${ }^{5}$, qui reflète surtout une perspective allemande plus tournée vers l'est depuis la chute du mur de Berlin, c'est un événement aujourd'hui partiellement oublié dans les pays de l'Ouest européen. Exemplaire de «l'histoire-batailles » reléguée aux oubliettes par l'école des Annales (et, avouons-le, par une historiographie française traditionnellement indulgente à l'égard de la politique extérieure de Louis XIV), l'historiographie du second siège de Vienne se réduit le plus souvent à des descriptions diplomatiques et des récits d'histoire militaire ${ }^{6}$. En effet, il semble difficile, si ce n'est impossible, d'échapper aux surinterprétations inhérentes à l'événement autrement qu'en se cantonnant aux fais avérés : combats, chiffres et péripéties diplomatiques. Et pourtant, une bonne mise en contexte politique et culturelle, qui tient compte de la longue durée, comme celle offerte récemment par Franco Cardini ${ }^{7}$, permet d'aller au-delà du simple récit factuel. Étudier la structure des premiers récits permet également de dépasser la mythographie, pour tenter de comprendre comment cet événement est révélateur d'un moment de transition politique et culturel crucial dans l'histoire de l'Europe.

7 En cette fin de XVII ${ }^{\text {e }}$ siècle, la guerre de course et les terrifiantes offensives ottomanes ne sont plus qu'un souvenir pour la plupart des européens. Depuis la bataille de Saint Gotthard en 1664, dans laquelle l'armée ottomane a été clairement battue, l'Empire ottoman est généralement considéré comme un monstre en décadence.

Depuis lors, les Ottomans n'étaient pas la première préoccupation de l'empereur Leopold $\mathrm{I}^{\mathrm{er}}$. Il espérait pouvoir facilement renouveler la trêve de vingt ans conclue en 1664 afin de pouvoir combattre la France, bien plus alarmante selon lui. Il est vrai que Louis XIV, qui domine largement l'ouest du continent à cette époque, menace directement l'Empire. En 1681, sous le nom de politique des Réunions, il commence à annexer directement les provinces à l'est du Rhin. La politique française est d'autant plus inquiétante pour Leopold que toute l'Europe attend la disparition prochaine du roi d'Espagne, le maladif Charles II, qui n'a pas d'héritier direct. Bien que son oncle l'empereur soit en première ligne pour la succession, il est clair que la France est en position de revendiquer une partie des territoires hispaniques. La période est dominée par les négociations et les opérations militaires destinées à préparer la juteuse succession de l'empire hispanique.

Pendant ce temps, Leopold doit faire face à d'autres problèmes sur la frontière est : depuis 1670, une nouvelle révolte protestante en Hongrie déstabilise la région, et finit par rendre la menace ottomane vraiment sérieuse à partir de 1678-1679 ${ }^{8}$. Le chef des rebelles, Imre Thököly, d'abord armé par les Français, choisit en 1682 de devenir le vassal de l'Empire ottoman. La situation alarme la Pologne, qui décide de rompre l'alliance française qu'elle avait conservée jusque là pour se rapprocher de l'Empire contre leur ennemi commun. Le grand vizir Kara Mustapha se saisit de l'occasion offerte par les désordres de Hongrie et décide de reprendre la guerre contre l'Autriche. Il n'est pas clair si le vizir, qui soigne l'ambition idéalisée du sultan, avait depuis le début l'objectif d'assiéger Vienne, ou seulement une forteresse de la frontière. Il envisageait peut-être d'engager un siège long, qui lui permettrait d'obtenir des concessions importantes de la part de l'empereur. Quoiqu'il en soit, en mai l'armée ottomane est à Belgrade. L'avancée inattendue de cette immense armée ravive les terreurs des siècles précédents. Les rumeurs de carnages et d'atrocités qui accompagnent son avancée changent la donne; les Turcs ne peuvent que gagner et dans les régions menacées, la terreur est bien réelle.

10 Le soutien le plus important de l'empereur est le pape. Alors que l'influence de l'Espagne décline en Italie, l'austère Innocent XI, qui se fait une haute idée de son statut et de sa 
mission, juge le moment favorable pour diversifier ses alliances et renforcer le rôle international de la papauté. Comme ses prédécesseurs, il finance largement l'armée impériale et surtout, depuis la paix de Nimègue en 1678 (dans laquelle il voit une perspective de paix en Europe), il fait d'énormes efforts pour convaincre les princes de s'unir et de combattre les Ottomans dans une nouvelle croisade'. Mais ces démarches diplomatiques n'ont pas un grand succès : les protestants refusent de s'allier à l'initiative papale et de nombreux Etats ne veulent pas s'engager dans une campagne sans profit direct, ou qui pourrait les compromettre vis-à-vis des Français ${ }^{10}$. Personne ne croit vraiment que les Turcs vont aller jusqu'à Vienne. C'est aussi pourquoi la défense de la ville prend longtemps à s'organiser. Tandis que l'on répare et renforce les fortifications, l'empereur rassemble une coalition majoritairement allemande, composée de princes dont les intérêts sont proches de l'Autriche, mais aussi d'un allié aussi utile qu'encombrant, qui partage les intérêts de l'empereur : la Pologne, dont la diète, après des hésitations, a accepté l'alliance avec l'Empire. Le roi Sobieski conditionne cependant son aide à la gloire d'être commandant en chef de l'armée. Finalement, Leopold accepte de céder sa place : prétextant la sauvegarde de la famille royale, il quitte Vienne pour Linz quelques jours avant le début du siège. Cette décision, perçue comme un abandon, lui sera vivement reprochée.

11 Mi-juillet, les Ottomans prennent position sous les murs de Vienne. Le conflit est marqué par des entreprises de minage, d'offensives et de contre-offensives quotidiennes, et par la proximité physique féroce entre assaillants et assiégés dans un conflit qui se prolonge. Début septembre, alors que l'une des murailles est sur le point de céder, la situation semble vraiment désespérée pour les Viennois accablés par la dysenterie et le découragement. Finalement, au tout dernier moment, l'armée de secours arrive. La bataille décisive a lieu le 12 septembre. À la fin de la journée, l'armée ottomane épuisée, surprise par la charge de la cavalerie polonaise, est prise de panique et fuit, laissant sur place ses prisonniers, tout son bagage et ses armements.

\section{Les nouvelles du siège}

12 Le siège et la victoire comportent plusieurs facettes, tonalités et temporalités, qui en font un événement médiatique unique, à la fois parce que le flot des nouvelles et des commentaires est immense et inédit, et parce que le siège et la victoire sont quasi immédiatement insérés dans une trame explicative et logique traditionnelle. Il est immédiatement interprété comme un fait symbolique, raconté comme un affrontement entre deux blocs politiquement, religieusement et ethniquement cohérents, la chrétienté occidentale et l'empire ottoman (qui conjugue l'islam et l'empire byzantin). À l'inquiétude et l'effroi, qui réactivent les vieilles peurs collectives et font écho aux situations de crise locales, suit le triomphe inespéré, réconciliateur et la gloire des héros. Par cette structuration idéologique qui contente un lectorat qui retrouve les accents épiques des romans de chevalerie et des gloires patriotiques, l'événement se trouve nommé, mis en forme, d'une manière si forte qu'elle n'a jamais cessé de se perpétuer jusqu'à nos jours.

13 Ce qui nous frappe, c'est à la fois l'abondance et la rapidité avec laquelle les nouvelles circulent : avant la fin septembre, des récits du siège, de ses célébrations, des poèmes, des louanges, des traités, etc., sont déjà publiés et copiés dans tous les principaux centres d'édition en Europe. La plupart de ces textes éphémères, édités à très peu d'exemplaires, 
ont disparu aujourd'hui. Toutefois, la circulation des textes ainsi que la multiplication des copies d'une formule à l'autre m'ont permis d'identifier jusqu'à présent plus de 300 textes publiés dans les semaines et les mois suivant la victoire, en huit langues différentes, y compris des dialectes.

La prépondérance de la langue et de la culture italienne à la cour de Vienne explique sans doute en grande partie la masse comme la structure de cette diffusion. Si l'italien était en effet employé dans l'ensemble de l'Europe au XVII ${ }^{\mathrm{e}}$ siècle, sans doute ne dominait-il nulle capitale autant que Vienne, petite métropole frontalière tournée principalement vers la péninsule et où l'on détestait les Espagnols peut-être autant que les Français. La gazette de la cour y parait en italien depuis $1671^{11}$. Cette prépondérance explique sans doute l'importance et la rapidité des informations qui parviennent en Italie, qui se fait la principale caisse de résonance des nouvelles, très vite rediffusées, pour toute l'Europe. Elle explique également l'importance des traductions. Pour prendre un exemple, les chroniques successives publiées à Vienne par l'imprimeur Jan Van Ghelen, héritier d'une lignée d'imprimeurs flamands installée dans la capitale autrichienne, dès la semaine qui suit la victoire, sont très rapidement publiées à Venise, d'où elles circulent en traduction française ${ }^{12}$. Le latin est donc loin d'être la première langue de diffusion des nouvelles du siège : si l'un des principaux récits, celui du flamand Pierre a Waelckeren, est publié dans cette langue (sans doute pour des raisons de facilité), c'est l'un des seuls. Il est d'ailleurs immédiatement traduit dans d'autres langues européennes, qui sont les vrais facteurs du succès du texte. Le latin arrive loin derrière les langues nordiques, est-européennes et même les dialectes ${ }^{13}$, dans lesquelles les chroniques du siège inondent le continent. Ce fait illustre bien l'avènement définitif d'une presse ouverte et accessible. Elle nous montre aussi une importante réalité de la circulation des informations et des réactions autour du siège de Vienne : alors que les traductions et copies se multiplient, reprennent les mêmes thèmes et chronologies, faisant de l'événement un fait international et standardisé dans sa forme, ses termes et sa structure, ces publications s'adressent à des publics de plus en plus restreints, géographiquement, socialement et politiquement parlant. Les thèmes et les styles conforment un genre international, intensément copié et adapté d'une région à une autre, mais les textes et leur intention sont conçus en fonction d'une clientèle définie à l'avance; ils reflètent et contribuent à définir une scène publique segmentée, des régions occupées d'intérêts différents.

15 Les principaux centres et réseaux d'information du temps sont naturellement actifs au siège de Vienne. Les grandes villes d'échange, comme Venise, Londres ou Amsterdam, impriment et diffusent les nouvelles de l'événement. Mais très vite, les centres secondaires sont bientôt les premiers à diffuser des textes imprimés : en particulier les petites villes italiennes comme Lucques, Modène ou Bologne, les villes allemandes du Rhin et les villes espagnoles périphériques (Barcelone ou Séville), un peu plus tard Lyon ou Toulouse en France. Ce basculement dans la géographie de l'information souligne à la fois la portée internationale inédite de l'événement, son importance en tant que produit commercial ${ }^{14}$, mais aussi la manière dont il se trouve immédiatement inséré dans les préoccupations locales et les objectifs de propagande. Le siège devient en effet presque instantanément un élément crucial des relations diplomatiques entre les pays ou les régions européennes: cette victoire inattendue, inespérée, ce sauvetage de dernière minute qui n'explique ni n'annonce rien en lui-même, devient un symbole et un argument qui sert à interpréter des contextes locaux et à soutenir des positionnements divergents. Aux petits États italiens qui subissent les pressions des grands États 
absolutistes, il donne l'espoir d'un rééquilibre des rapports de forces sur le continent. Dans les villes rhénanes, l'événement permet d'exprimer les mécontentements face à la politique agressive de Louis XIV ${ }^{15}$. Les villes périphériques d'Espagne quant à elles en appellent au renouveau de l'idéologie messianique, à la réforme qui permettra à l'Espagne retrouvera la gloire d'autrefois.

Les premières informations qui circulent sont tirées des lettres et des journaux rédigés par des témoins, soldats, diplomates ou fonctionnaires, restés sur place et servant pour la plupart les principaux protagonistes du siège. Les premières nouvelles sont donc déjà partisanes. L'importance symbolique de cette victoire explique en effet l'exploitation qui en est faite par ses principaux artisans, et d'abord le roi de Pologne Jean Sobieski et l'empereur. La première initiative du premier, après le pillage du camp ottoman et son entrée triomphale dans une Vienne infestée d'odeurs fétides et jonchée de morts, est en effet d'écrire plusieurs lettres semi-publiques qui établissent le récit de la victoire et vantent son rôle personnel.

D'autres témoins aussi écrivent immédiatement des lettres et des chroniques, qui parviennent en Italie dés le soir du 13 septembre, le lendemain de la victoire ${ }^{16}$. Très rapidement, ces témoignages de première main, qui viennent remplacer les rumeurs jusque-là omniprésentes, sont traduits et diffusés dans toute l'Europe. Ainsi, le journal détaillé du serviteur de l'armée impériale Vaelckeren, demeuré à Vienne pendant toute la durée du siège, est traduit en français, italien, allemand et anglais en l'espace de quelques mois à peine ${ }^{17}$. Des nouvelles signées ou anonymes, transitant par l'Italie, sont diffusées en France ou en Angleterre dans la semaine qui suit la victoire ${ }^{18}$.

Ces textes de première main sont à leur tour rapidement amplifiés et insérés dans des compilations ou des chroniques chronologiques, de format commercial, parfois illustrées, qui sont destinées à un public socialement et géographiquement précis. C'est le cas du Ragguaglio historico della guerra, publié par le puissant imprimeur Giovanni Giacomo Hertz à Venise et largement diffusé sur le continent ${ }^{19}$. D'autres textes de grande ampleur publiés en Italie, en Flandres et en Angleterre circulent ainsi dès la fin de l'année 1683.

Pour satisfaire des lecteurs en quête de nouvelles fraîches, au parfum d'authenticité, les imprimeurs adoptent volontairement la juxtaposition des styles : les lettres sont insérées dans le récit narratif, formule elle-même influencée par les chroniques informatives où la littérature donne la valeur du vrai. Ainsi le chroniqueur Vaelkeren, témoin direct des événements, affirme donner, après maintes vérifications des "bruits communs", une " histoire pure et vraie». Les termes "exact», "vrai », l'expression "corriger les erreurs " et "expliquer» sont omniprésents. Tout en multipliant les effets de réel (l'immédiateté, la multiplication des anecdotes, des voix discursives), les récits composent une information subjective, destinée à des publics sélectionnés.

Bientôt on retrouve ces compilations (augmentées des nouvelles les plus récentes) dans des régions plus éloignées du lieu des combats : c'est le cas par exemple de la Relación verdadera y compendio historial, une chronique de 23 pages publiée à Madrid peu après le 14 octobre 1683 (date des dernières informations que l'éditeur de la chronique affirme avoir reçues) ${ }^{20}$. En Espagne, la victoire de Vienne est d'ailleurs le point de départ de l'essor d'une presse locale jusque là bridée par l'isolement et la censure : elle permet de réactiver le premier journal périodique régulier, la très officielle Gaceta de Madrid, qui avait été interdite trois ans plus tôt, d'abord sous le titre de Nuevas ordinarias de los sucesos del Norte, puis sous d'autres titres ${ }^{21}$. Ces publications s'ajoutent aux chroniques étrangères, en particulier celles venues d'Italie, avec laquelle la péninsule entretient des liens 
intellectuels et commerciaux vitaux. Il en résulte des doublons et des ajouts merveilleux au milieu desquels la vérité, qui a finalement peu d'importance, finit de se perdre. Ainsi, le Floro historico de la guerra movida por el sultan de los Turcos Mehmet IV, publié par les imprimeurs Armendariz et Bremundan, se présente comme la traduction améliorée du déjà célèbre Ragguaglio historico de Gabriel Giovanni Hertz ${ }^{22}$. L' " amélioration » dont se vante l'auteur est dans la fin, qui permet dit-il de donner de la cohérence au récit. Par ailleurs, les Pays-Bas espagnols, situés dans la région de plus grand développement de la presse périodique et intermittente en Europe, publient également des gazettes en espagnol, qui sont ensuite réimprimées en Espagne ${ }^{23}$.

21 L'événement n'inspire pas seulement les publicistes : poètes et artistes s'emparent très vite d'un thème qui permet toutes les comparaisons historiques et symboliques et de flatter mécènes et politiques. À Florence, le poète Vincenzo Filicaia compose six chansons sur l'événement, dédiées au roi de Pologne, à l'empereur, à Charles de Lorraine et une en remerciement à Dieu $^{24}$. Dans un ton mélodramatique, le poète mêle rapprochements antiques et bibliques pour finalement glorifier l'empereur, véritable artisan de la victoire. À Bologne, des poèmes en dialecte local paraissent dans un joli volume illustré, qui reprend les récits factuels et insiste de façon distrayante sur le ridicule des Ottomans, la valeur des combattants ou encore la richesse du butin ${ }^{25}$. Très vite les artistes gravent et peignent la scène du siège et les valeureux commandants, dont les traits et les caractères font le tour de l'Europe.

Enfin, après les chroniques du siège et les poèmes élégiaques, circulent les récits des célébrations organisées par les villes européennes, en Italie en particulier, qui métaphorisent le combat contre les ténèbres musulmanes par la multiplication des récits de feux de joie. Les chroniques des combats qui se poursuivent continuent à paraître presque au jour le jour, intégrant souvent le récit du siège de Vienne. L'événement se prolonge ainsi dans des textes qui le démultiplient, l'actualisent en permanence, le transforment en moment fondateur, en clef du récit.

Les textes reprennent indéfiniment un certain nombre de grandes thématiques qui font de l'événement un révélateur précieux de la situation culturelle et politique du temps. Alors que la plupart des États ne participent pas au conflit, ils encouragent ou fomentent directement l'expression officielle d'anciennes angoisses et de frémissements émotionnels dans lesquels se réactualisent les anciens fantasmes de la croisade, les craintes de l'invasion barbare, et l'émotion de la victoire, utilisés de manière partisane dans les différents contextes locaux.

\section{La capitale assiégée}

Tout d'abord, ce sont les faits, les détails techniques, magnifiques et, au contraire, terrifiants (ou sensationnels) du siège qui fascinent un lectorat friand des récits de batailles. Cette passion pour ce que l'on appelait encore il n'y a pas si longtemps «l'art de la guerre $»^{26}$ doit se comprendre par l'existence d'une véritable culture aujourd'hui perdue, où s'exprime la culture nobiliaire, le patriotisme associé à la valeur héroïque des batailles et la proximité physique continue des individus au combat ou à ses répercussions. La guerre fait la valeur hiérarchique, l'histoire, la littérature de soldats et la poésie épique au service du pouvoir ; elle participe pleinement de la propagande, qui cherche à faire participer les populations de plus en plus imposées aux projets parfois contestables de la monarchie ${ }^{27}$. Cette fois la pièce de théatre qui est racontée est 
exceptionnelle : il ne s'agit pas du siège d'une petite place forte des Flandres, mais bel et bien de celui de l'un des "remparts de la Chrétienté », qui permet de reprendre la thématique médiévale de la forteresse assiégée, un thème identitaire partagé dans toute l'Europe $^{28}$. Ce n'est pas un affrontement entre chrétiens (toujours difficile à justifier), mais le combat de deux mondes, du bien et du mal, de la civilisation et de la barbarie, qui met en scène le vieux fantasme d'une possible inversion de l'histoire: au moment du siège, comme l'écrit Alphonse Dupront, Vienne devient «la troisième et dernière des villes de la croisade $»^{29}$.

Les premiers récits décrivent longuement les revues des troupes, leur composition, la beauté des uniformes, les banquets et la grandeur des généraux, les accords diplomatiques et les correspondances entre les princes, les offensives de minage et les contre offensives des défenseurs de la place, les morts, les blessés et les souffrances des civils. Le style des textes, informatif et crédible, souvent bien structuré, ne laisse pas la place aux fioritures. Sur huit pages serrées postées dès le 15 septembre, on décrit ainsi le siège de manière très technique, employant au besoin des abréviations ${ }^{30}$. La pompe, l'union chrétienne des soldats, leur détermination, sont soulignés pour montrer la valeur des troupes ${ }^{31}$. Puis on passe à la bataille décisive, à la gloire des généraux et des commandants, aux listes de soldats, de chevaux, de richesses gagnées dans le pillage qui suit la victoire.

Pour figurer plus précisément les choses, on y ajoute souvent des tableaux détaillés et des plans de la ville de Vienne (vues panoramiques, des fortifications, ou plus simplement, forme abrégée d'une forteresse), afin que le lecteur ne perde rien des différents épisodes et assimile la victoire à la symbolique pointue et étoilée des murailles défensives. Cette formule, reprise des panoramas flamands, est déjà traditionnelle à la fin du XVII ${ }^{\mathrm{e}}$ siècle : elle constitue en effet le principal succès commercial de ce type de littérature, éphémère et informative, depuis la guerre de Trente Ans. Le siège de Vienne se décline ensuite dans de multiples domaines des arts et des arts appliqués: tableaux, tapisseries, vases, assiettes, armes, etc. L'ample traité d'art militaire d'Allain Manesson-Mallet, abondamment illustré de croquis de places, d'armes et de fortifications, dont le premier tome parait en 1684, fait une large part aux guerres turques ${ }^{32}$. Les images renforcent les effets mais aussi la standardisation des interprétations de l'événement au niveau européen. 


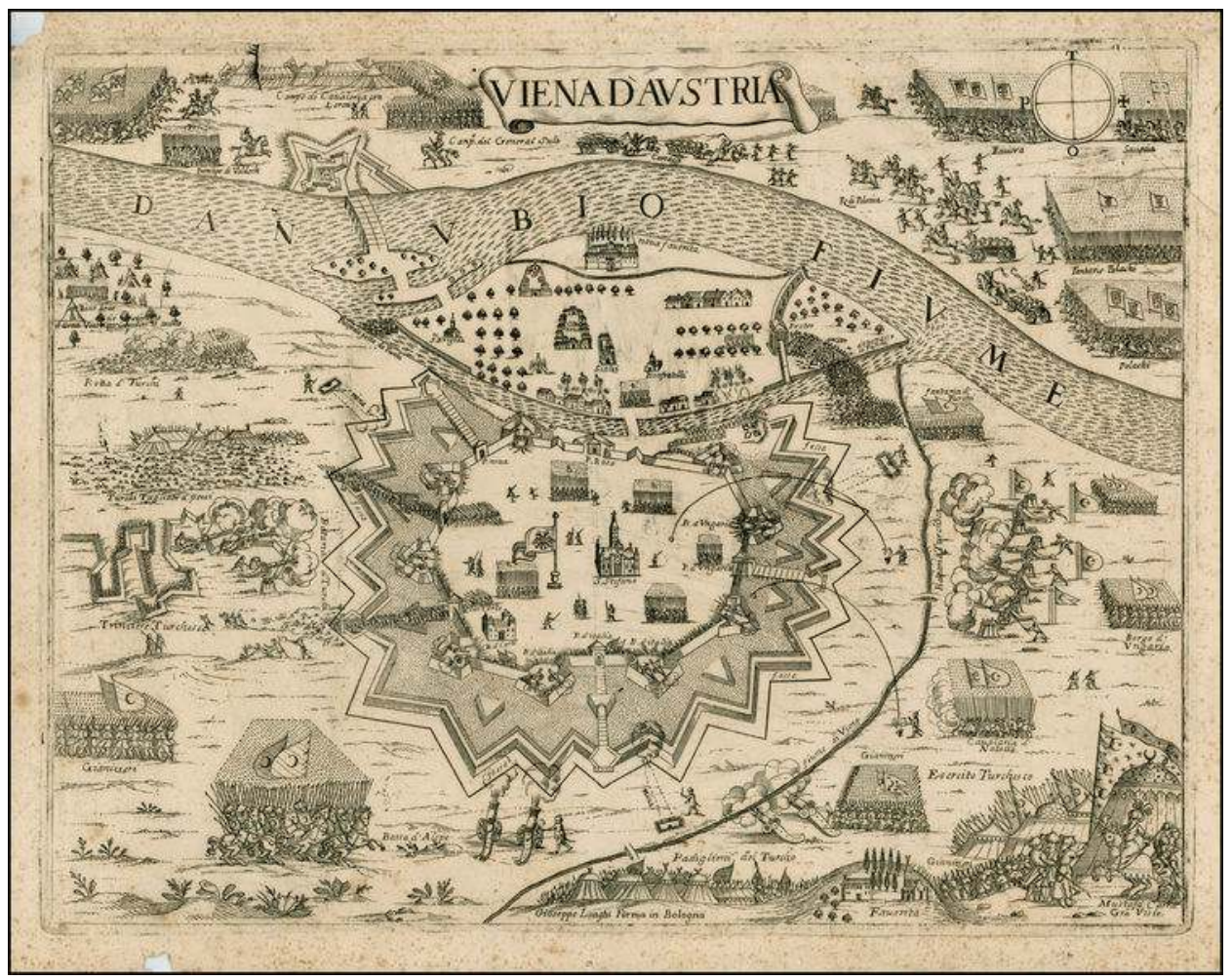

Bologne, $1683^{33}$.

Le siège raconté par les publicistes fait aussi la place au suspense et au sensationnel. L'horreur croustillante est bien présente: on s'égorge et on s'étripe pour le plus grand bonheur des lecteurs. Chez Hertz par exemple, l'ennemi est " coupé en morceaux », de très nombreuses manières. Mais si l'on tranche les têtes sans regret, on traite toutefois les blessés avec compassion : la guerre est question d'honneur et de manières. Les généraux quant à eux caracolent, dînent en chemin chez des connaissances, s'adressent aimablement la parole, triomphent au combat : la guerre racontée est certes sainte, mais elle obéit à une mise en scène minutieuse, avec ses intermèdes, ses actes obligés, ses codes de conduite.

Ce qui diffère toutefois ici des autres récits de siège contemporains, c'est l'insistance sur le pillage. Les descriptions détaillées des prises de guerres faites dans le camp ottoman abandonné précipitamment par les vaincus constituent en effet une partie essentielle des premiers textes. Des somptueux trophées jusqu'aux balles de laine, tout est soigneusement comptabilisé, chiffré dans des tableaux qui font apparaître non seulement la richesse du camp ottoman et la valeur militaire de la victoire, mais aussi l'exotisme d'un trésor véritablement fabuleux et étrange, tout en insistant sur la bonne organisation des distributions. Le détail des richesses dont on s'empare (d'abord décrites avec fierté par Sobieski, le premier à entrer dans le camp, dans la lettre semi-publique adressée à sa femme, la reine Casimire), donne aux récits une tonalité fascinante : perroquets, tentes de brocards, chevaux de race précèdent les descriptions des esclaves chrétiens délivrés dans le camp ottoman, des orphelins errant dans le camp vide et des femmes égorgées. Si dans les autres conflits, le pillage du camp ennemi, ou même celui des morts, constitue un fait accepté puisque le vaincu est abandonné par Dieu, on évite toutefois de trop insister sur 
des horreurs peu compatibles avec la nature chrétienne des victimes. D'ailleurs les conditions de la reddition, faites de manœuvres diplomatiques complexes, permettent souvent d'éviter d'en arriver là. Mais à Vienne, il est tout à fait légitime, puisque l'ennemi est un autre, il permet de souligner son humiliation.

Le pillage permet d'affirmer la victoire sur un ennemi en fuite, donc invisible. C'est pourquoi la bannière du grand vizir, le trophée le plus important, qui personnifie le chef ottoman qui s'est échappé, prend une telle place dans les textes. La perte de l'étendard est un signe fort de l'ampleur de la défaite, il est d'ailleurs amèrement souligné dans les chroniques turques. Plusieurs exemplaires de cette fameuse bannière sont distribués après le siège en Europe centrale et dans la péninsule italienne $e^{34}$. Le cas le plus célèbre est celui de l'étendard pris par le roi Sobieski dans le camp ottoman le jour de la victoire, qu'il offre en cadeau au pape. Sur la route qui la conduit à Rome, les villes italiennes célèbrent des fêtes et publient des images et des commentaires de cet objet militaire, mais perçu comme religieux puisqu'y apparaissent les marques emblématiques de l'islam (le croissant de lune et des inscriptions islamiques). Une description est publiée à Ferrare, des poèmes à Bologne, et le secrétaire originaire de Lucques Tommaso Talenti, chargé d'apporter ce cadeau au pape, est accueilli avec enthousiasme à Florence. À son passage à Bologne, la ville l'accompagne en cortège aux églises de la ville, avant de célébrer une longue exaltation du Saint Sacrement. La portée exotique de l'objet fait pendant à l'eucharistie, son reflet symbolique : l'étendard représente le corps du vizir, l'hostie le corps du Christ, triomphant et vengeur.

Un plus grand étendard, trouvé lui aussi dans le camp ottoman, est offert par le roi de Pologne au sanctuaire de Lorette, accompagné du baldaquin de la tente du grand vizir, dont on fait un dais processionnel ${ }^{35}$. La légende de fondation du sanctuaire associe en effet étroitement la Vierge à la croisade : la casa reale de Nazareth aurait été transférée miraculeusement en Italie après la conquête mamelouke de saint Jean d'Acre en 1291. Après la bataille de Lépante en 1571, le pape Pie V avait dédié la victoire à la Vierge du sanctuaire et lui avait accordé le titre d'Auxilium christianorum ${ }^{36}$. Ce don à la Vierge qui symbolise la résistance chrétienne à l'Islam, sert donc naturellement à intégrer la victoire de Vienne dans la saga des croisades. Il souligne aussi le triomphe de l'union italoautrichienne.

\section{Le culte des héros}

La victoire donne lieu à une véritable explosion de dithyrambes des grands généraux. On oublie bien vite que la victoire a été gagnée en une journée sur une armée ottomane épuisée par deux mois de siège et que la guerre est loin d'être achevée. Les acteurs de la victoire partout célébrés deviennent des caractères à la fois mythiques, internationaux et partisans : sauveurs de la Chrétienté, figurant la lutte entre deux mondes, ces figures désormais médiatiques permettent de servir des causes politiques en Europe.

Le triomphe du roi de Pologne, dont la cavalerie exotique, moustachue et terrifiante, est l'élément décisif de la victoire, est un grand sujet d'intérêt populaire et prend une bonne place dans les gravures, les poèmes et les chroniques. Sobieski en est lui-même le premier artisan. Le 15 août, il annonce sa décision de soutenir la défense de Vienne (après que l'empereur lui a laissé le commandement suprême) en des termes ampoulés : «j'ai décidé de monter sur mon cheval de bataille pour aller à la guerre sainte et rendre à Vienne assiégée son ancienne liberté ", écrit-il. Au lendemain de la victoire, il rédige des lettres 
triomphalement datées « depuis la tente du grand vizir, le 13 septembre » (« aussi grande que Varsovie » dit-il) à la reine, au marquis de Grana, le gouverneur espagnol des PaysBas, bien entendu au pape. Ces lettres immédiatement publiées et intensément copiées, décrivent «sa » victoire, ses prérogatives dans le pillage du camp ottoman et minimisent le rôle de l'empereur, absent de la bataille. Le victorieux Sobieski se décrit avec une modestie affectée en bras armé de Dieu et reprend une formule de César destinée à devenir sa marque de fabrique (et peut-être copiée sur le "Ut vidi vici » employé par Louis XIV lors du carrousel de 1662): «venit, vicit, Deus vincit». Sobieski appelle aussi à «la continuation de la guerre sainte » et à « la fin de l'empire de Mahomet ».

Récompensé de son concours par le pape, qui lui offre le titre de Défenseur de la Chrétienté ${ }^{37}$, les légendes et les mythes entourent bientôt le personnage, dont le prénom (Jean) se prête à une comparaison avec Jean le Baptiste. Sobieski devient le troisième Jean (après don Juan d'Autriche, le vainqueur de Lépante), un être providentiel, envoyé par Dieu, annonciateur de la victoire finale du catholicisme ${ }^{38}$. Ce souvenir s'est perpétué : l'imposant personnage peint en armure romaine dans les portraits officiels, devenu au cours des siècles un symbole de la défense nationale contre l'envahisseur, reste aujourd'hui l'une des gloires nationales polonaises. Le destin moderne de la nation effacée, partagée, plusieurs fois recréée, se retrouve dans le rôle fanfaron du roi tel que le présente Alfred Jarry dans Ubu Roi ou les Polonais, publié en 1896.

Bien qu'il ne soit pas un soldat, le pape est désigné comme le principal artisan de la victoire. Son rôle financier et diplomatique, comme sa valeur de rassembleur spirituel, sont pleinement reconnus par les textes, qui en font la tête d'une sorte de trinité héroïque.

Mais très vite, le héros le plus célébré est l'empereur. Malgré le fait qu'il n'était pas présent lors de la victoire, ayant dû laisser sa place à la tête de l'armée au roi de Pologne en échange de la participation de ce dernier, et alors qu'il était bien peu reconnu avant les événements ${ }^{39}$, l'empereur Leopold parvient rapidement à contrer la bruyante propagande de Sobieski. En quelques semaines en effet, les éloges établissent une hiérarchie des honneurs qui rétablit naturellement l'empereur comme principal artisan et bénéficiaire de l'alliance, de la bataille et de la victoire. Autour de lui, Sobieski, le duc Charles V de Lorraine (réfugié sans souveraineté au service de l'empereur depuis 1664), mais aussi le gouverneur de Vienne, le comte de Staremberg, deviennent des surhommes unis dans le même combat pour la foi, et offrent à l'Empire une nouvelle aura politique sur le continent.

Les images confortent cette hiérarchie: dans un grand nombre de gravures, comme le cycle de Romeyn de Hoogue consacré au siège de Vienne par exemple, l'empereur semble seul vainqueur, tandis que Sobieski, vite croqué dans un costume polonais folklorique, apparait comme un personnage secondaire. 
2. Romeyn de Hooghe Prise du grand Étendard et défaite entière des Turcs

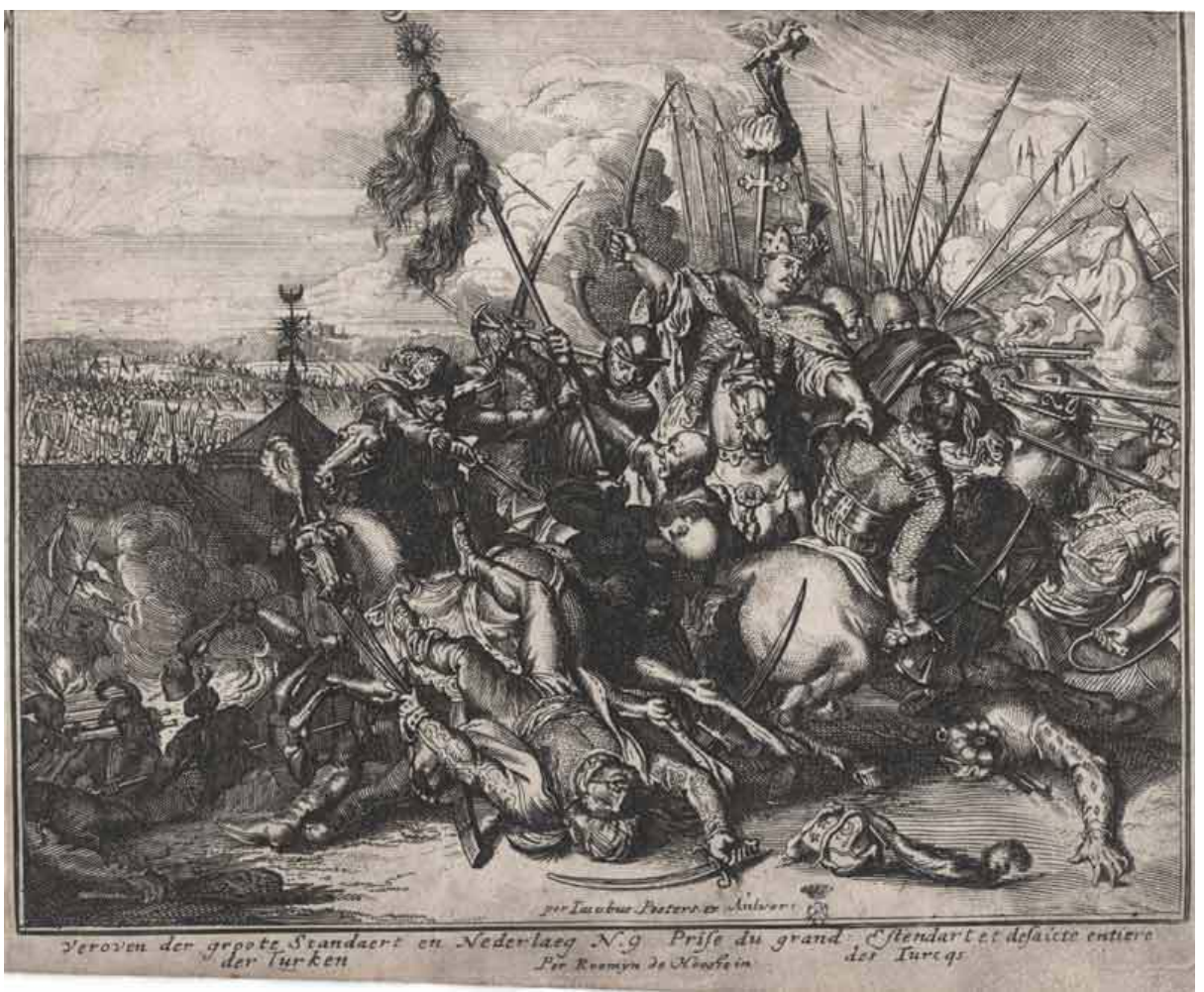

3. Romeyn de Hooghe, Entrée de S.M. Imp. dans la Tente du Grand Vizir ${ }^{40}$

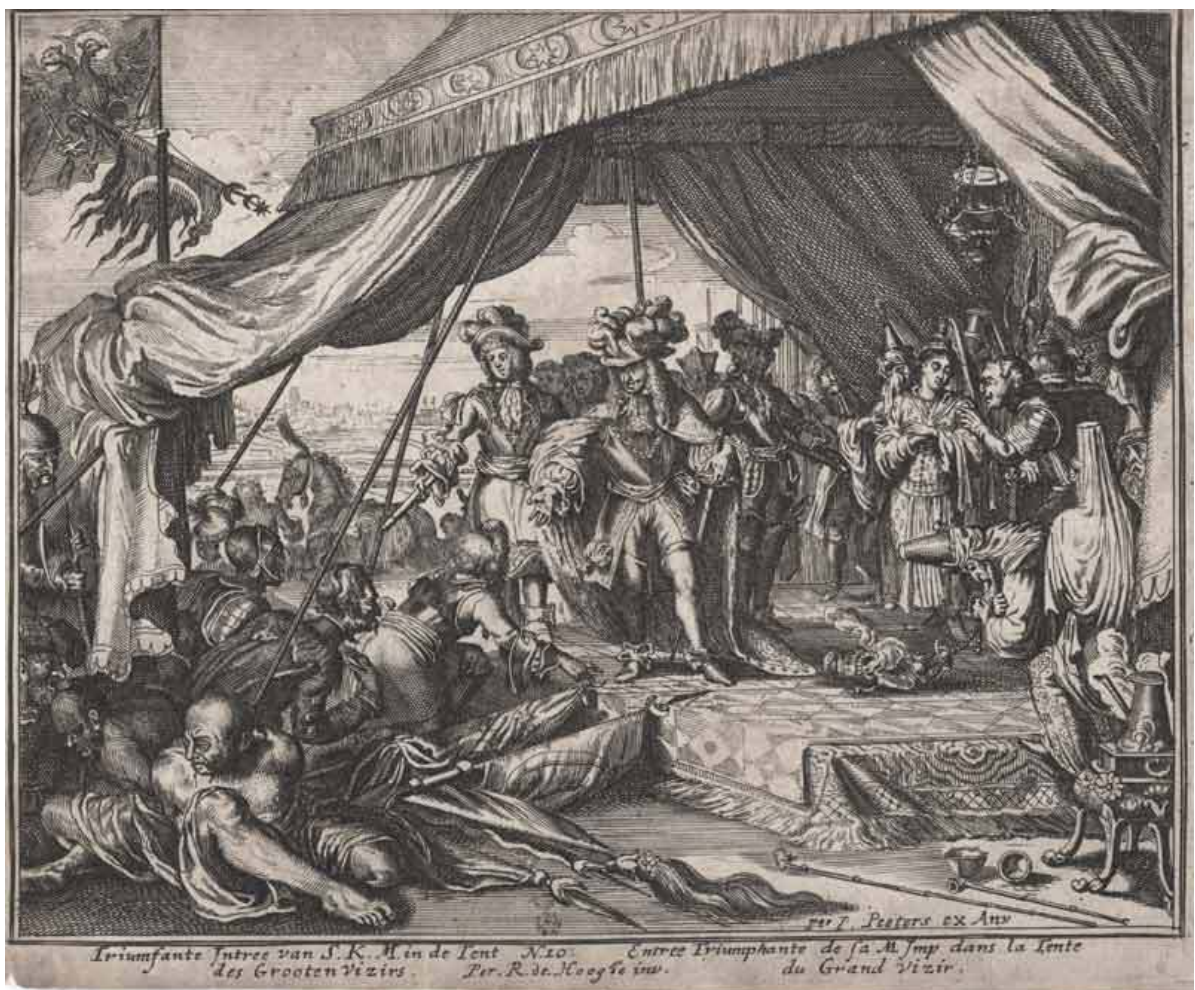

37 Dans ces textes sans nuance, la glorification des héros accentue par contraste le dénigrement des vaincus. Le grand vizir, dont la haute stature conserve un aspect 
terrifiant et mystérieux, est considéré comme le principal artisan de la guerre. Mais on cite surtout un personnage secondaire : le chef des rebelles hongrois, Imre Thököly. L'alliance qu'il a contractée avec les Turcs est considérée comme pire que la simple trahison, puisqu'il n'a pas seulement renié son suzerain, mais également sa foi. La victoire simplifie et éclaircit ainsi l'ensemble des enjeux et des positionnements : les manœuvres diplomatiques défavorables à l'Empire, les arguments de la France, ou l'approbation plus ou moins directe des révoltes hongroises, deviennent des manigances odieuses, contre l'intérêt de la chrétienté, naturellement catholique et favorable à l'empereur, bras armé de Dieu.

\section{Signes, dévotions et prophéties}

Dans un second temps, les récits, qui surfent sur le succès commercial inouï de l'événement, cherchent à livrer aux lecteurs assoiffés de nouveautés des explications plus secrètes, pas encore exprimées, autrement dit meilleures et plus authentiques, de cet événement extraordinaire. On insiste donc sur des détails, restés jusque là inaperçus mais désormais considérés comme significatifs : les présages, les signes naturels ou divins et les prophéties. Le succès de cette mythographie est assez fort pour avoir continué jusqu'à aujourd'hui. Ils réapparaissent en effet à l'époque des conflits balkaniques, dans les débats sur l'entrée de la Turquie dans l'Union européenne, ou encore des attentats du 11 Septembre 2001 à New York.

Les imprimeurs puisent dans un vaste répertoire de signes et de réminiscences traditionnels, sensés faire la preuve de l'intervention de Dieu dans l'histoire et qui permettent de lui donner un sens. La mise en récit des faits nécessite en effet de rattacher les événements les uns aux autres, donner un début et une fin, saler l'intrigue. Une fois la première surprise passée, la victoire n'est donc pas considérée comme un événement nouveau ou inattendu, susceptible de changer le cours de l'histoire dans une direction inconnue, mais comme un fait logique et attendu depuis toujours.

Les textes d'origine autrichienne et italienne soulignent très vite l'origine divine et la tonalité catholique de la victoire, insistant sur les liens entre l'Empire et la papauté, entre Dieu et son peuple. Le rôle joué par l'envoyé du pape, le charismatique frère Marco d'Aviano, qui bénit les troupes avant la bataille fatidique, est mis en avant dans ces textes idéologiques. Le geste du célèbre capucin, habile diplomate et prédicateur mais qui possède aussi une réputation de guérisseur thaumaturgique, rappelle l'action spectaculaire d'un carme espagnol avant la célèbre victoire de la Montagne Blanche, en $1621^{41}$. Le roi de Pologne insiste dans ses lettres sur un autre détail qui lui permet de s'approprier le soutien de Dieu : Marco d'Aviano aurait aperçu une colombe blanche avant la bataille, signe de la victoire. Mais d'Aviano est essentiellement le conseiller de l'empereur, il est son lien avec la papauté autant que son directeur stratégique et spirituel ${ }^{42}$ et son geste s'adresse à l'armée impériale dans son ensemble. La canonisation du franciscain Giovanni da Capestrano, le prédicateur de la croisade du XIV ${ }^{\mathrm{e}}$ siècle, en 1690, permet quelques années plus tard de magnifier le rôle de d'Aviano, lequel fut béatifié au milieu des polémiques en 2003.

41 Plus qu'aux actions humaines, une attention particulière est donnée aux signes qui auraient annoncé la victoire. Là encore, il y a des raisons commerciales pour lesquelles les textes du siège insistent tant sur les manifestations magiques de la divinité. Les prédictions concernant la fin du monde ottoman, qui se développent depuis le $\mathrm{XV}^{\mathrm{e}}$ siècle 
et le retour de la vague eschatologique, réactivées à chaque nouveau conflit, profitent de l'essor de l'imprimé et de la circulation des nouvelles au XVII ${ }^{e}$ siècle. Ce sous-genre sensationnaliste, particulièrement important à Venise, fait ainsi le tour de l'Europe ${ }^{43}$. Il y a aussi des raisons politiques plus immédiates : si la victoire a été prédite, elle peut ellemême aussi être un signe. En Espagne par exemple, où l'on cherche à alerter l'Europe catholique du risque que fait peser la France, le régime pro-autrichien de la reine Marianne d'Autriche insiste pour faire de la défense de Vienne un moment décisif, dont dépend la sauvegarde de la Chrétienté toute entière.

Les signes astrologiques et les comparaisons triomphales et antiques, sentimentales et lyriques, servent en effet des objectifs instrumentaux précis : la propagande impériale répond très vite au triomphe bruyant du roi de Pologne. On rappelle que Vienne, petite capitale frontalière (alors que les capitales de la plupart des États modernes se trouvent au centre de leur territoire) d'un empire fortement diminué depuis les traités de Westphalie, a hérité le titre de " pomme d'or » donné autrefois à Constantinople. Son rôle de « verrou de la Chrétienté » en fait un enjeu capital, emblématique pour l'ensemble des Européens ${ }^{44}$. On voit opportunément réapparaitre d'anciennes prophéties qui proclament la gloire de l'empereur. Celle de Nicolas Drabicius par exemple est immanquablement mentionnée dans les chroniques du siège. On cite aussi celle du jésuite Martino Strigonio, véritable matraquage idéologique lancé par l'empereur pour montrer qu'il est le seul auteur de la victoire. La prophétie, qui date de 1649, annonce en effet la naissance d'un empereur qui non seulement anéantira les Turcs mais devra affronter la France, avant de triompher de tous. Les étoiles se bousculent dans le ciel impérial; certains auteurs annoncent même une conjoncture stellaire favorable jusqu'en 1802. Tous ces pronostics, si communs en Europe, reflètent la nouvelle grandeur d'un empereur jusque là en fort mauvaise posture et qui après la victoire de Vienne apparaît désormais comme un grand prince européen. Ils donnent aussi une touche pseudo-scientifique à la victoire inespérée de Vienne, qui contrebalance la valeur spécifiquement confessionnelle des signes divins, et s'adresse aussi bien aux catholiques qu'aux protestants. La propagande souligne aussi la supériorité idéologique de l'empereur sur Louis XIV, le « roi très-chrétien » qui a refusé de prendre part dans cette guerre sainte, condamné comme un allié machiavélique des Ottomans.

Les textes se font l'écho complaisant des rumeurs les plus invraisemblables, toutes bonnes à communiquer. Celle de l'apparition miraculeuse sur le lieu de la bataille d'une croix portant l'acrostiche AEIOU (pour "Austriae Est Imperatore Orbis Universo », « Austriae Erunt Imperii Ottomanici Victores", ou encore "Austriaci Emmanuel, Iohannes, Odalescus Veneti») montre l'amplitude de l'imagination du prolifique imprimeur Gian Carlo Mattesillani, à Bologne ${ }^{45}$.

Les dates sont naturellement aussi des signes prisés : le 8 septembre, jour de la nativité de la Vierge, tandis qu'a lieu la revue générale des troupes coalisées, les Viennois implorent un miracle aux pieds de la colonne de la Vierge, la Mariensäule et le même soir, leur appel au secours reçoit enfin une réponse. En Espagne, le roi reçoit la nouvelle de la victoire le 2 octobre, veille de Notre Dame du Rosaire et de la bataille de Lépante, comme le souligne un texte espagnol ${ }^{46}$. En 1682, époque où la comète de Halley traverse le ciel européen, deux comètes très catholiques sont interprétées après-coup comme annonciatrices de machinations huguenotes en France, et de la victoire de Vienne. On suit là une tradition éprouvée, qui remonte à la chute de Constantinople et revient en force au moment du pic de publications et de relations qui suit la bataille de Lépante, en 1571: la reprise de 
certains vieux thèmes joachimites, mais aussi des oracles de Léon le Sage, prépare la formation d'un terrain iconographique et idéologique apocalyptique, dans lequel la Vierge prend une place fondamentale. La dévotion pour la Vierge amica sole connaît un succès tout particulier en Espagne et dans les régions catholiques de l'Empire où les jésuites mènent une reconquête catholique active. Vierge immaculée et Vierge de la Victoire, cette dévotion universaliste et standardisante associe les deux versants de l'universel et du local, grâce à la supériorité de son pouvoir et à son identification aisée avec les Vierges autochtones. Emblème déjà traditionnel des Habsbourg au milieu du XVII e siècle, elle apparaît sur les bannières impériales comme généralissime des armées, conformément à un vœu datant de 1676 et renouvelé peu avant la défense de Vienne. Cette présence très confessionnelle est immédiatement exploitée par les envoyés papaux, qui font de la Vierge le lien entre les victoires de Lépante et de Vienne. Le 7 octobre devient le jour de Notre Dame de la Victoire, puis du Rosaire, dévotion alors en pleine expansion et à forte tonalité anti-islamique: il s'agit ici d'une guerre juste et d'une victoire chrétienne, qui prend place dans une longue série d'événements miraculeux offerts aux chrétiens par un Dieu qui les protège.

Les textes qui diffusent les prophéties et les célébrations catholiques ont un rôle considérable dans la diffusion de cette dévotion mariale ${ }^{47}:$ "selon ce que nous affirme un texte ", lit-on dans une relation sévillane de 1683, c'est la Vierge du Rosaire qui a soutenu les armées chrétiennes à Lépante, puis à Vienne. Et le culte de la vierge du secours, présente sur de nombreuses colonnes commémoratives dans toute l'Europe centrale, essaime rapidement dans les années suivantes.

Mais signes et prophéties ne se cantonnent pas à la sphère catholique. La longue relation historiographique de Jean-Baptiste de Rocoles, un curieux personnage passé plusieurs fois d'une confession à l'autre et longtemps exilé en Allemagne et en Flandres, se fait l'écho de toutes les rumeurs et on-dit en la matière. Alors qu'il se moque avec dédain de la " crédulité » des catholiques, il les reprend pourtant en détails. Il mentionne même par exemple une solive qui serait apparue dans le ciel au-dessus du camp ennemi, signe du châtiment divin ${ }^{48}$. Au-delà de la simple propagande politique, ces prophéties témoignent ainsi des profonds bouleversements qui affectent les perceptions de la réalité en cette fin de XVII ${ }^{\mathrm{e}}$ siècle ${ }^{49}$. Quelques années plus tard, Pierre Bayle dédie d'ailleurs au curieux Drabicius ( fameux enthousiaste du XVII e siècle»), prophète défroqué du triomphe de l'empereur Leopold, un chapitre détaillé de son Dictionnaire historique et critique ${ }^{50}$. L'ancien pasteur devenu prophète pour mieux prédire la fin de la maison d'Autriche, se voit ici exhumé mais cette fois en faveur de l'empereur, dans une conjoncture historique nouvelle, avant de provoquer l'ironie de Bayle.

\section{Les Turcs pendant et après le siège}

Certains des textes qui circulent à cette occasion font partie d'une catégorie plus large de productions « anti-turques ", fruits de circulations en Europe qui intéresse aujourd'hui de plus en plus de chercheurs ${ }^{51}$.

Dès le $\mathrm{XV}^{\mathrm{e}}$ siècle, lorsque le monde ottoman s'intègre définitivement dans le paysage européen, il bénéficie d'images contrastées, qui accompagnent une réalité de relations diplomatiques, commerciales et conflictuelles toujours poursuivies. Avec l'éloignement progressif de la menace militaire au cours de l'époque moderne, on observe un décalage grandissant entre les discours stéréotypés et figés, qui datent des premiers contacts du 
Moyen Âge et de la Renaissance, et la réalité des contacts commerciaux, culturels ou diplomatiques ${ }^{52}$. À la fin du XVII ${ }^{e}$ siècle, l'empire ottoman est généralement considéré comme un empire en décadence qui, selon le modèle antique de la translatio imperii, devra un jour ou l'autre laisser la place à une nouvelle puissance. En France, le discours du pouvoir utilise abondamment ce thème, qui permet de grandir la figure de Louis XIV, amené à devenir le nouvel empereur européen, pourfendeur des Turcs et surtout successeur de la monarchie universelle espagnole ${ }^{53}$.

En dépit d'une grande ignorance, l'intérêt pour le fonctionnement interne de l'empire ottoman grandit pourtant dans la deuxième moitié du siècle : les relations politiques et commerciales et l'apparent déclin militaire ottoman s'accompagnent en effet d'une curiosité nouvelle $\mathrm{s}^{54}$. Pourtant la description des "Turcs", perçus, en dépit de la nature multiethnique de l'empire, comme un groupe générique identifié à une foi méconnue jugée hérétique et infantile, au turban, à la moustache, à l'épée et au symbole négatif du croissant de lune, reste empreinte d'un profond mépris, y compris chez les philologues et les théologiens ${ }^{55}$. Le Turc reste l'ennemi par excellence, celui dont l'Europe a justement besoin dans cette période de bouleversements politiques. Et c'est cette seule image que véhiculent les chroniques du siège de Vienne. Dans ces récits, le Turc apparaît sous un masque simplifié de cruauté, de barbarie (c'est-à-dire de sauvagerie), et comme un "dévoreur de royaumes" à l'orgueil excessif (stéréotype qui provient de l'idée de l'usurpation des Lieux Saints). Perfide, il ne combat pas pour la gloire mais pour la rapine. Alors que l'on insiste sur l'union religieuse des chrétiens, on nie aux Turcs toute foi religieuse : selon Vaelckeren, Dieu donne la victoire aux armées chrétiennes sur les «armées païennes qui se confiaient sur leurs propres forces». Cette image négative apaise les craintes, conforte les préjugés et sert des enjeux partisans. La défaite conforte la certitude du déclin de l'empire : déclin militaire, mais aussi moral, qui correspond à la pratique des péchés capitaux, au manque de valeur et au raffinement dans la cruauté. Par ailleurs les Turcs, partisans d'une guerre injuste, qui cachent leurs intérêts malveillants sous des arguments religieux et divisent pour mieux régner, figurent en réalité les Français, qui sont les premiers et véritables ennemis de l'Empire, commanditaire des textes.

Cependant, les récits des témoins directs du siège donnent aussi une image différente, étonnamment proche, de l'adversaire. À Vienne, en dépit des privations et des minages quotidiens, la proximité des deux camps favorise en effet une familiarité paradoxale: depuis la ville, on entend les prières organisées dans le camp ennemi, les célébrations turques, "accompagnées d'horribles instruments et de hurlements ${ }^{56}$ ». On a le temps d'observer les techniques, d'admirer l'endurance et la mise en place des stratégies, d'entendre les hommes parler et de voir les visages des morts. Finalement, on admire l'opiniâtreté de l'adversaire, qui renvoie en miroir l'image du courage et de l'adresse des assiégés.

51 Les récits insistent aussi sur les erreurs stratégiques multipliées des Ottomans. Et très vite après la surprise de la victoire, la fuite honteuse de l'armée ouvre la porte aux railleries et au mépris des Turcs, bientôt diabolisés dans les textes italiens et espagnols. La description chiffrée de l'immense butin laissé par l'ennemi est la démonstration de l'ampleur de la défaite. Reflet du soulagement incrédule des vainqueurs, la description éblouie du camp ottoman et surtout du luxe dont s'entourait le grand vizir, se fait extravagante: on mentionne des bains, le jardin équipé d'une fontaine artificielle et d'animaux d'agrément (des perroquets, des dromadaires et même une autruche !). Puis, tandis que les impériaux 
pourchassent les fuyards, des textes concentrent leur attention sur les Turcs. Des lettres et des récits annexes, des faux grossiers, viennent alimenter le flot des publications. Ces textes sont à leur tour repris et compilés et ainsi largement diffusés. C'est le cas par exemple des Memorias historicas de los monarcas othomanos, un pamphlet traduit du florentin et publiée à Madrid en 1684 qui qualifie le système politique ottoman de machiavélique; ou encore du Manifeste sacrilège ${ }^{57}$, prétendue déclaration de guerre du sultan, publié pendant le siège. Après avoir cité toute une titulature pompeuse et ridicule (roi du Paradis, possesseur du sépulcre de votre Dieu, persécuteur des chrétiens, etc.), Mahomet IV se dit décidé à conquérir toute la terre, à pendre les prêtres, à s'emparer de l'empereur, et autres méfaits tout aussi aberrants. Ce texte probablement d'origine italienne se fait l'écho des sentiments de haine d'un lectorat convaincu d'avance. Publié de nouveau à la suite de la victoire, il joue du plaisir de l'humiliation de l'adversaire, grotesque dans ses prétentions manquées, et s'achève par le souhait d'une prochaine victoire totale « comme à Covadonga, quand quatre pauvres Espagnols, avec leur glorieux Pelayo, humilièrent l'arrogance ottomane (sic) ${ }^{58}$ ".

Enfin, bien que les textes européens soient truffés de signes et de prophéties, on l'a vu, les Turcs sont qualifiés de superstitieux lorsque leur armée perçoit des signes négatifs à l'approche de Vienne. Pour les auteurs, il n'y a pourtant nulle contradiction ici, puisque le signe n'est légitime que lorsqu'il vient de Dieu. Les textes insistent ainsi sur l'idée d'une opposition radicale entre deux mondes, qui n'a pour but que de renforcer l'identification catholique, impériale, romaine ${ }^{59}$. Cette dimension idéologique est particulièrement sensible dans les descriptions, commentaires et traductions de la bannière du sultan, dans lesquelles les connaissances philologiques et religieuses des auteurs ne servent qu'à démontrer l'incompatibilité des deux univers ${ }^{60}$. Dans un texte publié à Rome et à Bologne ${ }^{61}$, le célèbre orientaliste Ludovico Marracci, futur traducteur-pourfendeur du Coran en latin, confesseur du pape et expert en textes orientaux auprès de la papauté, reprend un argumentaire remontant au $\mathrm{X}^{\mathrm{e}}$ siècle : l'islam, secte qui réfute la Trinité, est l'œuvre du libidineux Mahomet ${ }^{62}$. 


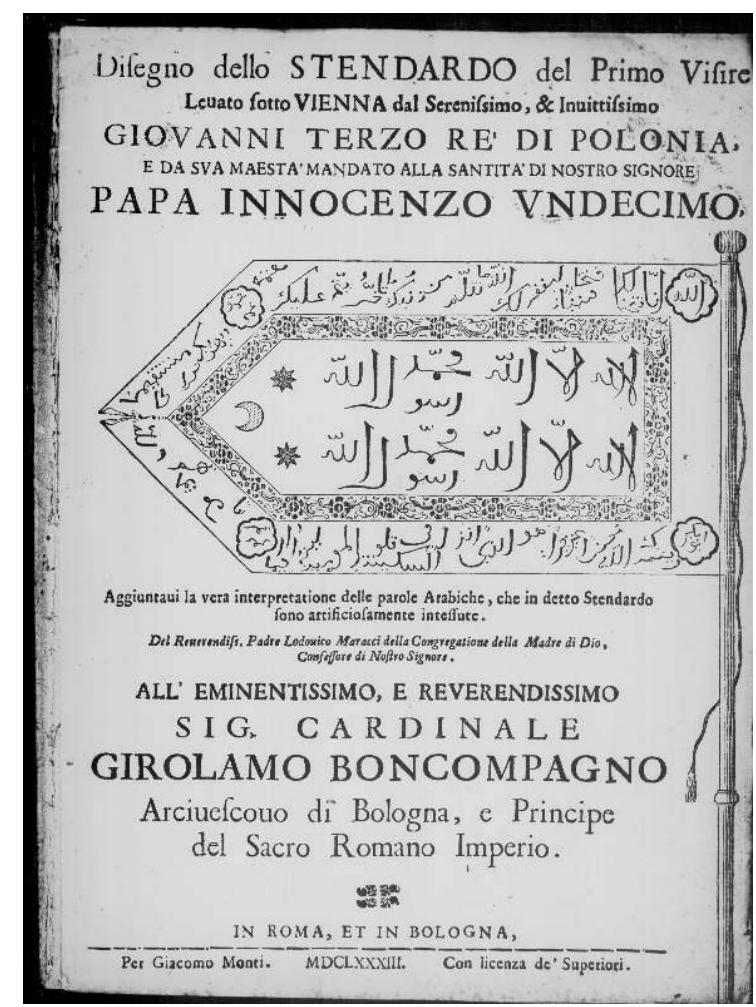

Bologne, 1683.

Les Turcs, "vils descendants d'Agar ", constituent un topos traditionnel rassurant, qui conforte les valeurs d'identification pour une population inquiète: dans un monde en profonde transformation, ils servent à faire exister par contraste une chrétienté solidaire et triomphante, au profit de Rome et de la propagande autrichienne.

\section{Conclusion}

L'étude des grands thèmes qui apparaissent de manière si récurrente et si forte dans tous les récits publiés autour de la victoire de Vienne nous permet de saisir l'importance des processus de communication des affaires internationales dans l'Europe de la fin du XVII siècle. En dépit de moyens limités, les nouvelles circulent, sont copiées, traduites, réinsérées dans de nouveaux récits, à une vitesse fulgurante. On entrevoit également la proximité et la complexité des relations entre les intérêts commerciaux et partisans, tout comme la variété des prises de parti dans une Europe en pleine transformation. Comme c'est évidemment toujours le cas aujourd'hui (et en cela la mutation des médias ne semble pas être en cause), les événements internationaux sont d'abord décrits et commentés dans un contexte local, dans lequel ils ont le rôle de commenter, donner un sens à une situation précise, faire écho à des préoccupations présentes, que l'on aurait du mal peutêtre à décrire ou à formuler. Certains d'entre eux, comme c'est le cas du second siège de Vienne, prennent une dimension inédite parce qu'ils deviennent la caisse de résonnance de préoccupations partagées, et qu'ils sont nécessaires à la communication politique cette fois à un niveau suprarégional. C'est là que réside l'intérêt de se pencher sur la temporalité et le contexte communicationnel de faits qui apparaissent à priori nimbés 
d'une épaisse mythographie. Entre une première indifférence, des périodes d'intense ferveur, la volonté d'être partie prenante de l'événement et de se sentir membre d'une vaste communauté imaginaire, les textes du second siège de Vienne nous dévoilent une Europe où se juxtaposent des scènes publiques très diverses mais intimement liées par des intérêts à la fois commerciaux, culturels et idéologiques.

Le paroxysme émotionnel et la frénésie éditoriale de 1683 se poursuivent dans les années suivantes. Ils s'étendent aussi sur le continent européen, et jusque dans les colonies d'Amérique, où l'on célèbre des jubilés pour la victoire de Vienne. La formation de la Sainte Ligue entre l'Autriche, la Pologne et Venise, en 1684, a lieu dans une atmosphère qui rappelle les anciennes croisades. Puis la prise de Buda deux ans plus tard donne lieu à un déferlement inédit du nombre et du genre des publications : c'est véritablement là que l'on peut situer la naissance de la presse moderne, qui sera le grand tournant des Lumières. Cette passion accompagne la reprise des conflits entre les Européens et fournit en réalité la matière idéologique pour des conflits partisans. La presse européenne antifrançaise en particulier y trouve le signe de la fin de la domination unilatérale de Louis XIV et manifeste l'espoir grandissant d'un repositionnement des rapports de force sur le continent. Après 1686 toutefois, les guerres «austro-turques» passent au rang de nouvelles secondaires. Le risque d'invasion qui fit trembler l'Europe centrale et l'Italie est vite passé, vite oublié avec la succession des campagnes d'une guerre qui s'éloigne et se prolonge pendant plus d'une décennie.

La véritable portée du siège de Vienne se réduit ainsi à un cadre temporel et géographique précis, limité à quelques mois de l'été 1683 et à une partie de l'Europe centre-orientale. Très vite aussi la stupeur, les passions antiturques et l'émerveillement se taisent, aussi soudainement qu'ils étaient apparus. En 1699, la paix de Karlowitz souligne le retrait des Ottomans et l'avènement de Vienne non plus comme véritable capitale territoriale, qui rétablit l'équilibre des forces en Europe. Mais c'est aussi le déclin définitif de Venise et de la mer Egée, et celui du pouvoir conciliateur du pape. La croisade comme perspective historique vraisemblable semble bel et bien appartenir à une époque révolue. Parallèlement, le retrait territorial de l'empire ottoman ébranle les obstacles de l'incompréhension culturelle. Jusque là craints et observés avec un mélange d'effarement et d'ignorance, les Turcs sont bientôt considérés avec un regard neuf. Dans les années suivantes, l'intérêt pour l'empire ottoman s'en trouve profondément renouvelé.

\section{NOTES}

1. La recherche qui concerne la presse ancienne et des autres modes de communiquer et d'informer avant le XVIII ${ }^{\mathrm{e}}$ siècle est aujourd'hui en plein essor et s'intéresse à des dimensions très variées. Pour ne mentionner que les aspects politiques et de circulation des nouvelles, voir notamment : Paul Arblaster, Antwerp \& the World: Richard Verstegan and the International Culture of Roman Catholicism, Louvain: Leuven University Press, 2004 ; Christian Jouhaud, Mazarinades, la Fronde des mots, Paris: Aubier, 1985 ; Kevin Sharpe, Steven Zwicker (dir.), Reading, Society and Politics in Early Modern England, Cambridge : Cambridge University Press, 2003 ; Joop W. Koopmans 
(dir.), News and Politics in Early Modern Europe, Leuven : Peters, 2005 ; Mario Infelise, « Roman avvisi : information and politics in the seventeenth century », in Gianvittorio Signorotto et Maria Antonietta Visceglia (dir.), Court and Politics in papal Rome 1492-1700, Cambridge : Cambridge UP, 2002, p. 212-28 ; Pierre Civil et Daniel Boillet (éds.), L'actualité et sa mise en écriture aux $X V^{e}, X V I^{e}$, XVII ${ }^{e}$ siècle. Espagne, Italie, France et Portugal, Paris : Presses de la Sorbonne Nouvelle, 2005.

2. La généalogie du renouveau de l'appropriation de l'événement est bien retracée par François Dosse, Renaissance de l'événement, Paris : PUF, 2010. Pour une étude de cas dans l'Europe moderne, voir Hans Medick et Pamela Selwyn, "Historical Event and Contemporary Experience: The Capture and Destruction of Magdeburg in $1631 »$, History Workshop Journal, n52, 2001, p. 23-48.

3. Sur les événements médiatiques, voir Daniel Dayan et Elihu Katz, Media Events: The Live Broadcasting of History, Harvard : Harvard University Press, 1992.

4. Il existe des ouvrages bibliographiques qui recensent ces publications : Walter Sturminger, Bibliographie und Ikonographie der Türkenbelagerungen Wiens 1529 und 1683, Graz, Köln : H. Böhlaus Nachf, 1955, compte 3300 titres pour le second siège, mais dans une fourchette de temps et d'espace plus étendue que celle que nous avons choisi de considérer ici. Voir aussi Heinrich Kábdebo, Bibliographie zur Geschichte der beiden Türkenbelagerungen Wiens 1529 und 1683, Wien: Faesy \& Frick, 1876.

5. Pim den Boer, Heinz Duchhardt, Georg Kreis, Wolfgang Schmale (dir.), Europäische Erinnerungsorte 2 : Das Haus Europa, München : Oldenbourg Verlag, 2011.

6. Les ouvrages sont très nombreux et ne cessent de paraître, la frénésie éditoriale se trouvant régulièrement réactivée par les anniversaires (1883, 1983 en particulier), les conflits, mais aussi les relations de l'Europe avec la Turquie et plus largement avec le monde musulman.

7. Franco Cardini, Il turco a Vienna (1683), Roma : Laterza, 2011.

8. Pour un récit détaillé des événements, voir Franco Cardini, Ibidem ; John Stoye, The Siege of Vienna: The Last Great Trial Between Cross \& Crescent, London: Collins, 1964 ; Obstlt. Georg von Hoffmann, Relation du siège de Vienne par un officier de la garnison (1683), in : Ferdinand Stoller (éd.), Neue Quellen zur Geschichte des Türkenjahres 1683 aus dem Lothringischen Hausarchiv, Innsbruck : Wagner, 1933.

9. Ludwig von Pastor, The History of the Popes, vol. XXII, London : Kegan Paul, Trench, Trubner \& CO, 1940 ; Bruno Neveu, "Culture religieuse et aspirations réformistes à la cour d'Innocent XI ", in : Accademia e cultura. Aspetti storici tra Se e Settecento, Firenze : L. S. Olschki, 1979, p. 235-276.

10. Sur les efforts diplomatiques du pape et les modalités des réponses des différents pays, voir les études menées par Gaetano Platania, en particulier (à partir des archives vaticanes) : «Le corti d'Europa e il pericolo turco (1683) attraverso l'inedita documentazione conservata nei fondi archivistici romani e vaticani ", Est (d')Europa, 2010, en ligne, http://www.culturenetwork.info/ estdeuropa/articoli/21; Gaetano Platania (dir.), L'Europa di Giovanni Sobieski: cultura, politica, mercatura e società : atti del VI Colloquio Internazionale, Viterbo 24-26 giugno 2004, Viterbe : Sette città, 2005.

11. L'emploi de cette langue permet à l'élite impériale de limiter l'accès à l'information (pas toujours favorable) aux élites lettrées. Umberto De Bin, «Leopoldo I, imperatore e la sua corte nella litteratura italiana ", Boletino del circolo academico italiano di Vienna, Trieste, 1910 ; Gaetano Platania (dir.), La cultura latina, italiana, francese nell'Europa centro-orientale: atti del V Colloquio internazionale, Viterbo 9-11 ottobre 2003, Viterbe : Edizioni Sette Città, 2004.

12. Vera relazione del combattimento e vittoria dall'armi cesaree, e polacche, in Vienna Appresso Gio. Van Ghelen et in Venetia, appresso Iseppo Prodocimo. / Relation véritable du combat et de la grande victoire remportée contre les Turcs... de Venise, slnd. Voir Anthonie Abraham Vorsterman van Oyen, Les Van Ghelen, imprimeurs, Gand : Vanderhaeghen, 1883.

13. En bolonais ou en patois de Liège par exemple. Voir Jean Haust (dir.), « Une " paskeille " liégeoise de 1683 sur le siège de Vienne ", Dialectes belgo-romans, Bruxelles, janvier-mars 1937, p. $15-28$. 
14. Mario Infelise, «El mercado de las noticias en el siglo XVII: las tipologías de la información » in: John Amelang et Antonio Castillo Gómez, Opinión pública y espacio urbano en la Edad Moderna, Gijón : Trea, 2010, p. 153-163.

15. Sur la presse francophone à l'étranger sous Louis XIV, voir Elizabeth Eisenstein, Grub Street Abroad: Aspects from the French Cosmolitan Press from the Age of Louis XIV to the French Revolution, Oxford: Oxford University Press, 1992.

16. Avviso manoscritto di Polonia con corriero e gentil'uomo di sua Maestà Cesarea spedito alla santità di nostro signore all'Eminentissimo Pio, BAV., Barb. Lat. 692, cit. Mirella Mafrici, Rapporti diplomatici e scambi commerciali nell'Mediterraneo moderno, Fisciano: Rubbetino, 2004. Les courriers semipublics, adressés à des destinataires précis mais appelés à circuler publiquement, sont l'une des formes les plus courantes de l'information du temps.

17. Par exemple : Pierre à Vaelckeren, Vienne assiégée par les Turcs et délivrée par les Chrestiens, ou Journal du siège de Vienne depuis le 6. de may de l'année 1683 jusqu'au 15. de septembre de la mesme année, composé en latin par,... Avec des figures. Bruxelles, $1684 ;$ A relation or diary of the siege of Vienna. Written by John Peter a Valcaren, judge-advocate of the Imperial army. Drawn from the original by His Majestie's command. London, 1684.

18. Copia di lettera scritta dal campo sotto Viena a Bologna dall IllmoGio Carlo Mattesillani, residente della Maesta del Re di Polonia... in Bologna e in Piacenza, 15 settembre 1683 ; Journal des opérations de l'armée impériale sur le Danube, daté de Vienne, 14 septembre 1683, Fiorenza e Siena : stamp. del publico, 1683; Relatione della segnalata vittoria ottenutta dall'armi Cesaree... in Milano, per Marc'Antonio Pandolfo Malatesta, 1683 ; ou encore Sincero racconto de' consigli et operationi... degli assadiati di Vienna, Venise, 1683.

19. Ragguaglio historico della guerra trà l'armi Cesaree, e Ottomane dal principio de la ribellione degl' Vngari sino l'anno corrente 1683, e principalmente dell'assedio di Vienna, e sua liberazione, etc., in Venetia, Gio: Giacomo Hertz, 1683.

20. Relación verdadera y compendio historial en que se comprehenden todos los sucessos de la guerra..., Madrid, 1683. Hallarase en la Puerta del Sol.

21. Voir Manuel Fernando Chaves, «Entre quality papers y prensa amarilla : Turcos, Moriscos y renegados ", in : Relaciones de sucesos en la BUS, antes de que existiera la prensa, Sevilla : Universidad de Sevilla, 2008, p. 82-94.

22. Sebastian de Armendaríz, Fabro Bremundan, Floro historico de la guerra movida por el sultan de los turcos Mehmet IV. Contra el augustísimo Leopoldo primero, emperador de romanos, el año 1683.

23. Javier Díaz Noci, «El Mediterráneo en guerra. Relaciones y Gacetas españolas sobre la guerra contra los turcos en la década de 1680 ", in : Pierre Civil et al. (dir.), España y el mundo mediterráneo a través de las Relaciones de Sucesos (1500-1750), Salamanca: Universidad de Salamanca, 2008 ; id., «Gacetas españolas de los Países Bajos en el siglo XVII. La Gazeta de Amsterdam y Noticias Principales y Verdadera ", Ámbitos, 7-8, 2002, p. 215-237.

24. Une première édition parut à Florence en 1684 : Canzoni in occazione dell'assedio e liberazione di Vienna.

25. Voir Arturo Nagy, Eco bolognese della guerra di liberazione in Ungheria, 1683-1686. Bologna: Parma, 1943.

26. Le récit de siège était si important qu'à certaines périodes il a pu constituer la majeure partie de la production imprimée. Voir Hélène Duccini, « La guerre de Trente Ans en France : discours et représentations ", Le Temps des médias, n4, 1/2005, p. 137-150.

27. Franco Cardini, La culture de la guerre, Paris : Gallimard, 1992 ; David García Hernán, « Guerra, propaganda y cultura en la monarquía hispánica: la narrativa del Siglo de Oro », Obradoiro de historia moderna, $\mathrm{n}^{\circ} 20,2011$, p. 281-302 ; Hervé Drévillon, Batailles: scènes de guerre de la Table Ronde aux Tranchées, Paris : Seuil, 2007 ; Jean-Pierre Rorive, La guerre de siège sous Louis XIV en Europe et à Huy, Bruxelles : Racine, 1998. 
28. Sur les préjugés, les prédictions et les craintes européennes vis-à-vis du monde ottoman à l'époque moderne et leur évolution, la bibliographie est immense. Voir Mustafa Soykut, Italian Perceptions of the Ottomans: Conflict and Politics through Pontifical and Venetian Sources, Frankfurt am Main : Peter Lang, 2011 ; Alexandra Merle, Le miroir ottoman: une image politique des hommes dans la littérature géographique espagnole et française (XVI ${ }^{e}-\mathrm{XVII}{ }^{e}$ siècles), Paris: Presses Paris Sorbonne, 2003; Lale Babaoglu Balkiş, «Defining the Turk: Construction of Meaning in Operatic Orientalism ", International Review of the Aesthetics and Sociology of Music 41, no2, déc. 2010, p. 185-193 ; Franco Cardini, Europa e Islam : Storia di un Malintenso, Roma : Laterza, 1999 ; Gabriele Haug-Moritz et al. (dir.), Repräsentationen der islamischen Welt im Europa der Frühen Neuzeit, Münster : Aschendorff, 2010.

29. Alphonse Dupront, Le mythe de croisade, Paris : Gallimard, 1993, p. 516.

30. Copia di lettera scritta dal campo sotto Vienna a Bologna... Bologne, 1683.

31. Par exemple, datant d'après la conclusion de la nouvelle ligue après la Victoire de Vienne : Relacion verdadera, en que se da noticia de las grandes prevenciones, y aparatos de guerra con que ha salido a campaña el exercito del invictissimo señor emperador Leopoldo Ignacio de Austria... 1683.

32. Allain Manesson-Mallet, Les travaux de Mars, ou l'art de la guerre divisez en trois parties... Avec un ample détail de la Milice des Turcs, tant pour l'Attaque que pour la deffense, La Haye: Chez Henri Van Bulderen, 1696.

33. Voir E. Bellucci, V. Valerio, Piante e vedute di Napoli dal 1600 al 1699. La città teatro, Napoli : Electa Napoli, 2007.

34. Le détail des sources a été étudié par Gaetano Platania (éd.), L'Europa centro-orientale e il pericolo turco tra Sei e Settecento, Viterbo : Sette città, 2000.

35. Notificazione del regio stendardo Turco mandato deal re di Polonia alla Santa Casa di Loreto, Ancona 1684.

36. Voir Yves-Marie Bercé, Lorette aux $\mathrm{XVI}^{e}$ et XVII ${ }^{e}$ siècles: histoire du plus grand pèlerinage des Temps modernes, Paris: PU Paris-Sorbonne, 2011 ; Emanuela Properzi Giovanni Rocchi, La santa casa da Nazareth a Loreto. Una storia imperniata tra Fermo e Venezia. Una novità su sant'Anna e sancta Angula, Monsampietro Morico : PNL, 2007.

37. Sur les relations diplomatiques et le rôle de la Pologne, voir les études dirigées par Gaetano Platania, en particulier Venimus, vidimus et Deus vicit : Dai Sobieski ai Wettin : la diplomazia pontificia nella Pontificia nella Polonia di fine Seicento, Cosenza : Ed. Periferia, 1992.

38. Bronislaw Bilinski, Le glorie di Giovanni III Sobieski vincitore di Vienna nel 1683 nella poesia italiana, Roma : Accademia polacca delle scienze, 1990 ; Salvatore Canneto (dir.), Il turco, l'assedio di Vienna, la poesia italiana (1683-1720), Roma : Università di Roma, 2012.

39. Voir Maria Goloubeva, The Glorification of Leopold I in Image, Spectacle and Text, Mainz : P. von Zabern, 2000.

40. Copyright : Université de Liège (Belgique) - Collections artistiques.

41. Sur le geste du carme espagnol Domenico de Jesus Maris, voir Olivier Chaline, La bataille de la Montagne Blanche (8 novembre 1620). Un mystique chez les guerriers, Paris : Noesis, 2000 ; Voir Marco d'Aviano e il suo tempo. Un cappuccino del Seicento, gli Ottomani e l'Impero. Atti del convegno storico internazionale (Pordenone, 1993), Pordenone : Concordia Sette, 1994.

42. Les lettres échangées entre les deux hommes au cours de l'été 1683 montrent le poids que Leopold donnait à ses conseils. Onno Klopp (éd.), Corrispondenza epistolare tra Leopoldo I., imperatore, ed il P. Marco d'Aviano, Capuccino, Graz : libreria Styria, 1888.

43. Kenneth Meyer Setton, Western Hostility to Islam and Prophecies of Turkish Doom, Philadelphia :American Philosophical Society, 1992; Augustin Redondo, Christine Aguilar, La prophétie comme arme de guerre des pouvoirs, $\mathrm{XV}^{e}-\mathrm{XVII}{ }^{e}$ siècles, Paris : Presses Sorbonne Nouvelle, 2001.

44. Eve Menk-Bertrand, L'image de Vienne et de Prague à l'époque baroque (1650-1740). Essai d'histoire des représentations, Strasbourg : PUS, 2008. 
45. Gian Carlo Mattesillani, Lo scudo impugnato por la FEDE Della SRM du Giovanni III di Polonia... Bologna, 1683.

46. Salida en publico, a cavallo, del rey nuestro señor don Carlos Segundo, que Dios guarde...1683.

47. Voir Biagio della Purificazione, Narrazioni delle piu insigni vittorie riportate dai fedeli per intercessione della SS. Madre di Dio dagl'anni di Cristo 534 fino al 1683, Rome, 1687.

48. Jean-Baptiste de Rocoles, Vienne deux fois assiégée par les Turcs, La Haye : Jean Prins, 1684.

49. Euan Cameron, « Enchanted Europe: Superstition, Reason, and Religion, 1250-1750 », English Historical Review, CXXVII(526), 2012, p. 718-720.

50. Pierre Bayle, « Drabicius », in Dictionnaire historique et critique t. VI, Paris : Desoer, 1820 (1702), p. 1.

51. Ana María Carabias Torres, «La producción editorial sobre el Imperio Otomano y los turcos en España (1470-1850). Una investigación in fieri ", Tiempos modernos: Revista Electrónica de Historia Moderna 7, $\mathrm{n}^{\circ} 20,2010$, p. 1-35.

52. Voir note 27, et Miguel Ángel de Bunes Ibarra, La imagen de los musulmanes y del norte de Africa en la España de los siglos XVI y XVII: los carácteres de una hostilidad, Madrid : CSIC, 1989 ; Bo Stråth, Europe and the Other and Europe as the Other, New York : Peter Lang, 2010.

53. Guido Braun, La connaissance du Saint-Empire en France, 1643-1756, München : Oldenbourg, 2010.

54. Gerald MacLean, The Rise of Oriental Travel : English Visitors to the Ottoman Empire, 1580-1720, Basingstoke: Palgrave, 2003; Daniel Goffman, The Ottoman empire and Early Modern Europe, Cambridge : Cambridge University Press, 2002.

55. Voir Faruk Bilici, «L'Islam en France sous l'Ancien Régime et la Révolution: attraction et répulsion ", Rives nord-méditerranéennes [En ligne], 14 | 2003, URL : http://rives.revues.org/406.

56. Vaelckeren, op. cit.

57. Relacion verdadera, en que se refiere el sacrilego manifiesto, Manifiesto sacrilego, y blasfema arrogancia con que Mahometo Quarto, tyrano emperador de los Turcos, publico guerra universal..., Madrid, 1683, 1684.

58. Cette comparaison fait référence à la première victoire du royaume des Asturies sur l'armée Omeyyade en 722, considérée comme le début de l'offensive des royaumes du Nord contre l'AlAndalus musulmane.

59. Voir Giovanni Ricci, «Da Lepanto a Passarowitz. Echi dello scontro con gli Ottomani sulla religiosità e la cultura popolare in Italia », in : Bernard Heyberger, Mercedes García-Arenal et al. (dir.), L'Islam visto da Occidente. Cultura e religione del Seicento europeo di fronte all'Islam, Atti del convegno internazionale, Milano, Università degli Studi, 17-18 ottobre 2007, Milano : Marietti, 2009, p. 159-169.

60. Disegno dello standardo del primo vizire levato sotto Vienna... Bologna, 1683. On trouve également un dessin et une description dans le Ragguaglio histórico, op. cit.

61. P. Lodouico Maracci, Disegno dello stendardo del Primo Visire Leuato sotto Vienna dal Serenissimo, \& Inuittissimo Giovanni Terzo re' di Polonia, e da sua maestà mandato alla santità di nostro signore Papa Innocenzo Vndecimo, Aggiuntaui la vera interpretatione delle parole Arabiche, che in detto Stendardo sono artificiosamente intessute... In Roma, et in Bologna. Per Giacomo Monti. MDCXXXIII.

62. L'insistance réitérée sur la sensualité musulmane conforte l'idée rassurante d'une faiblesse générale de l'empire ottoman en déclin. Voir Giovanni Ricci, «Fantasie sessuali sul turco nella prima età moderna. Qualche scheda", in: Felice Gambin, Alle radici dell'Europa : mori, giudei $e$ zingari del Mediterraneo occidentale, Firenze : Seid, 2009, p. 255-264; Aslı Çırakman, From the "Terror of the World" to the "Sick Man of Europe" : European Images of Ottoman Empire and Society from the Sixteenth Century to the Nineteenth, New York : Peter Lang, 2002. 